\title{
Blackseed (Nigella sativa) Oil and its Active Ingredient, Thymoquinone, Suppress the Aggressive Phenotype of Breast Cancer Cells
}

\author{
Sabrina Chaudhry, Safia Siddiqui, Tyrnnon K. Steffen, Stacey L. Raimondi* \\ Department of Biology, Elmburst College \\ Students:sabrina.chaudbry@365.elmburst.edu,safia.siddiqui@365.elmburst.edu,tyrnnon.k.steffen@365.elmburst.edu \\ Mentor:*raimondis@elmburst.edu
}

\begin{abstract}
Breast cancer is a leading cause of cancer deaths in women within the United States. However, current treatment methods for the disease present deleterious side effects themselves. Therefore, there is a move towards finding natural cures in order to mitigate negative side effects while still providing effective treatment for the cancer. Blackseed (Nigella sativa) oil is one particular natural remedy, alongside its active ingredient thymoquinone (TQ), which has been successfully tested for suppressing certain types of breast cancer cell proliferation. TQ itself has been seen to be capable of preventing proliferation of both non-aggressive MCF-7 and highly aggressive MDA-MB-231 cancer cells. However, studies which looked at the effects of TQ on MCF-7 cells alone were limiting in their use of high concentrations of the chemical without emphasis on finding a minimum effective dosage. Additionally, a second study which tested the effects of TQ on both MCF-7 and MDAMB-231 cell lines conducted the experiments in the presence of a lipid-carrier molecule. This, in turn, may have served as a confounding variable in the results. Therefore, it was hypothesized that a minimal effective dosage for both blackseed oil and TQ could be determined, where a significantly greater suppression of MDA-MB-231, in comparison to MCF-7, cell proliferation would be observed. Cell proliferation, cell adhesion, and soft agar assays were used to test the hypothesis of this study. The minimum effective dosage for each substance, characterized by proliferation of the non-aggressive MCF-7 cells to some extent and suppression of the aggressive MDA-MB-231 cells, were determined to be $0.5 \mu \mathrm{L}$ for blackseed oil and 1.0 $\mu \mathrm{M}$ for TQ. Additionally, TQ's effectiveness was noted to be more time-dependent than blackseed oil. This study supports the use of minimal effective doses for blackseed oil or TQ to naturally treat breast cancer while preventing damage to nonaggressive cells.
\end{abstract}

\section{KEYWORDS}

Breast cancer; Blackseed oil; Nigella sativa; Thymoquinone; Effective dose; Natural remedies

\section{INTRODUCTION}

Breast cancer currently stands as a leading cause of cancer-related death in women within the United States, second only to lung cancer, and has been estimated to cause 40,890 deaths in the year 2016. In addition, an estimated 249,260 new breast cancer cases are expected to be seen this year. ${ }^{1}$ Aside from skin cancers, breast cancer is also the leading form of cancer in US women, responsible for approximately $30 \%$ of all new cancer diagnoses. ${ }^{2}$ Two forms of breast cancer exist, based on differences in tumor location: invasive and non-invasive. Non-invasive forms of breast cancer are characterized by abnormal cell growth that does not extend beyond the originating layer of cells. Invasive breast cancer cells, however, are those that proliferate beyond the walls of glands or ducts in which they originate, and subsequently invade nearby breast tissue. ${ }^{2}$ In the case of non-invasive breast cancers, the 5-year survival rate for females reaches as high as $99 \%$, whereas that for invasive cancers that have infiltrated distant tissues of the body is as low as $26 \%{ }^{2}$ These statistics speak to the importance of all attempts to find a cure to breast cancer in general, but more pressingly, to find a means of suppressing aggressive breast cancer cell growth.

Recent studies have found numerous negative side-effects associated with common chemotherapeutic agents used in treating breast cancer. These include such effects as ototoxicity, cardiotoxicity, infertility, premature menopause, osteoporosis, and other similarly deleterious ailments. ${ }^{3,4}$ As recent studies expound upon the many negative side effects of current drugs used in treating breast cancer, a shift toward more natural remedies for cancer treatment has been seen. One natural remedy that has recently been making a comeback in the field of medicine for treating various cancers is Nigella sativa oil, also known as blackseed or black cumin seed oil. Having been used mostly in areas of the Asian continent for decades, blackseed oil has 
been hailed for its position as a medical cure-all. ${ }^{5}$

In recent research, blackseed oil has been seen to suppress cancer cell proliferation and/or viability in a number of cancers, including cancer of the colon, lungs, pancreas and several other cancers. ${ }^{6-9}$ Thymoquinone (TQ) has been noted to be the major chemical component of blackseed oil, with thymol, dithymoquinone, and various tocopherols accounting for the other major chemical components of the oil. ${ }^{10}$ In particular, TQ is known to have important antioxidant and antimicrobial properties that are thought to contribute to the many health benefits of blackseed oil. ${ }^{5}$ Intriguingly, TQ alone has even been seen to display cancer-fighting ability against cancers of the larynx, colorectal area, brain, breast, oral lining, blood, and a number of other cancers.9,11-17 In the study testing the effects of TQ on the non-aggressive MCF-7 breast cancer line, however, it was noted that very high concentrations of TQ were used as treatments (ranging from 0 to $80 \mu \mathrm{M}$, at $10 \mu \mathrm{M}$ increments). ${ }^{14}$ This leads to a lack of knowledge regarding minimal effective dosage of the chemical. In another study using breast cancer cell lines, while both the non-aggressive MCF-7 and highly aggressive MDA-MB-231 cells were tested, these tests were run with the presence of a lipid carrier molecule, which may have affected the results of a study carried out without said component. ${ }^{15}$

Given that very high doses of TQ are capable of causing death of even non-aggressive MCF-7 cells, while the effects of TQ on MDA-MB-231 cells has not, to our knowledge, been tested in the absence of a lipid carrier molecule, it would prove valuable to find the lowest effective doses of TQ and blackseed oil capable of preventing MDA-MB-231 cell proliferation while exhibiting a lesser effect on non-aggressive MCF-7 cells. ${ }^{14}$ Thus, this study will serve to provide data regarding the potential effects of blackseed oil and its active ingredient, TQ, on both MCF-7 and MDA-MB-231 breast cancer cells. Considering the previous literature, it is hypothesized that both blackseed oil and TQ will suppress the growth of both MCF7 and MDA-MB-231 breast cancer cells at high doses, whereas a low dose of each compound will preferentially suppress growth of the aggressive MDA-MB-231 cell line compared to the non-aggressive MCF-7 cell line.

\section{MATERIALS AND METHODS}

\section{Cells and culture conditions}

MCF-7 and MDA-MB-231 breast cancer cell lines were obtained from ATCC. These cell lines were chosen because they are some of the most commonly used breast cancer cell lines available and were used in previous research so that we can compare our results to others. Furthermore, they show two different sides of breast cancer - a non-aggressive/non-invasive cell line, MCF-7, which maintains virtually all of the characteristics of normal breast epithelia with regard to hormone receptor status, cell morphology, and growth patterns compared to an invasive/metastatic cell line, MDA-MB-231, that has lost its epithelial cell patterns including hormone receptor status, cell morphology, and growth patterns. All cells were cultured at $37^{\circ} \mathrm{C}$ and $5 \% \mathrm{CO}_{2}$ in complete media containing RPMI 1640 (Life Technologies, Grand Island, NY), 10\% FBS (Life Technologies), and 1\% Penicillin-Streptomycin (Sigma-Aldrich, St. Louis, MO). Blackseed oil was obtained commercially and directly added to cell cultures in the amounts indicated. Thymoquinone (Sigma-Aldrich) was diluted in DMSO (Sigma-Aldrich) to create a $1 \mathrm{mM}$ stock solution and added to cell cultures in the concentrations indicated. In order to determine minimal effective doses of blackseed oil and TQ to be utilized in the following assays, previous research was used to determine a suitable range for study. ${ }^{7-9,11,12,14-17}$ Following this, comparative dose-response experiments for each solution were run to find respective minimal effective concentrations. These were defined by the two lowest solution concentrations at which a majority of cancer cell death was observed, without completely eliminating all cells. For blackseed oil, these values were at $0.5 \mu \mathrm{L}$ or $1.0 \mu \mathrm{L}$ of blackseed oil, while for TQ the values were found to be $1.0 \mu \mathrm{M}$ or $5.0 \mu \mathrm{M}$ of thymoquinone.

\section{In vitro cell proliferation assay}

Cells were plated in a 6 -well dish at a density of $1 \times 10^{5}$ cells, in $2 \mathrm{~mL}$ of media, per well. All cells were counted and re-plated twice a week for one week. Treatment groups were given $0.5 \mu \mathrm{L}(0.5 \mu \mathrm{L} / 2 \mathrm{~mL})$ or $1.0 \mu \mathrm{L}(1.0 \mu \mathrm{L} / 2 \mathrm{~mL})$ of blackseed oil, or $1.0 \mu \mathrm{M}$ or $5.0 \mu \mathrm{M}$ of thymoquinone with little to no separation out of the solutions from the media. A control without DMSO (data not shown) and with DMSO, using an equal amount of pure DMSO as used to prepare the $1 \mathrm{mM}$ stock solution, were run as well. All controls worked as expected with no difference in growth between the untreated and DMSOonly controls. Experiments were done in triplicate.

\section{In vitro cell adhesion assay}

To measure cell adhesion, $1 \times 10^{5}$ cells were plated, in $2 \mathrm{~mL}$ of media, in each well of a 6 -well dish and allowed to adhere for 30 minutes following treatment with blackseed oil or thymoquinone. Treatment groups were given either 0.5 or $1.0 \mu \mathrm{L}$ of blackseed oil, or 1.0 or $5.0 \mu \mathrm{M}$ of thymoquinone with little to no separation out of the solutions from the media. Cells were subsequently washed with PBS and counted to determine adhesive ability. A control without DMSO (data not shown) and 
with DMSO, using an equal amount of pure DMSO as used to prepare the $1 \mathrm{mM}$ stock solution, were run as well. As stated above, the controls worked as expected with no difference between DMSO alone and an untreated control. Experiments were done in triplicate.

Soft agar assays

Soft agar assays were performed, as previously described, to measure anchorage-independent growth using $1 \times 10^{5}$ cells in 3 $\mathrm{mL}$ of media for each treatment. ${ }^{18}$ Treatment groups were given 0.5 or $1.0 \mu \mathrm{L}$ of blackseed oil, or 1.0 or $5.0 \mu \mathrm{M}$ of thymoquinone with little to no separation out of the solutions from the media. A DMSO-only control was also utilized following the concentrations used in previous experiments (see above). Experiments were done in triplicate.

\section{RESULTS}

Blackesed oil and thymoquinone decrease cell proliferation in aggressive breast cancer cells

In order to determine the minimal effective doses of blackseed oil and TQ to allow suppression of aggressive cell growth, with minimal negative effects on non-aggressive cell growth, a range of concentrations of blackseed oil and TQ used in previous experiments was utilized on MCF-7 and MDA-MB-231 cells (data not shown)..$_{-9,11,12,14-17}$ Within this range, the minimal effective dose of each compound was determined to be $0.5 \mu \mathrm{L}$ and $1.0 \mu \mathrm{L}$ of blackseed oil and $1.0 \mu \mathrm{M}$ and $5.0 \mu \mathrm{M}$ of thymoquinone. In order to determine the effects of these minimal effective doses of blackseed oil and thymoquinone on the cell growth of MCF-7 and MDA-MB-231 breast cancer cell lines, cell proliferation was measured. Cells were allowed to proliferate for a week and counted on the third and seventh day. When grown in the presence of 0.5 and $1.0 \mu \mathrm{L}$ of blackseed oil, there was no significant difference seen between the MCF-7 control and treatment groups (Figure 1A). However, there were significant differences found between the MDA-MB-231 control, $0.5 \mu \mathrm{L}$, and $1.0 \mu \mathrm{L}$ treatment groups for blackseed oil (Figure 1B). MCF-7 cells treated with 0.5 and $1.0 \mu \mathrm{M}$ of TQ also displayed no significant differences from the control (Figure 1C). MDA-MB-231 cells treated with $5.0 \mu \mathrm{M}$ TQ exhibited significant differences when compared to the control group, but 1.0 $\mu \mathrm{M}$ TQ showed no significant differences (Figure 1D). In general, MDA-MB-231 cells were affected more greatly than MCF-7 cells by treatment with blackseed oil and thymoquinone.
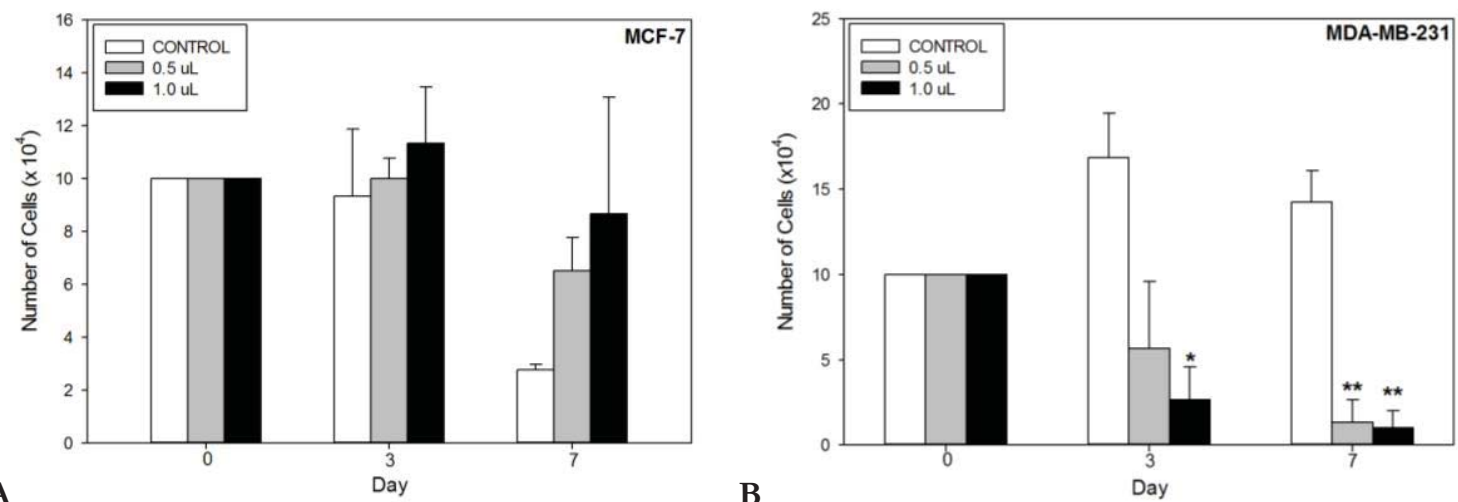

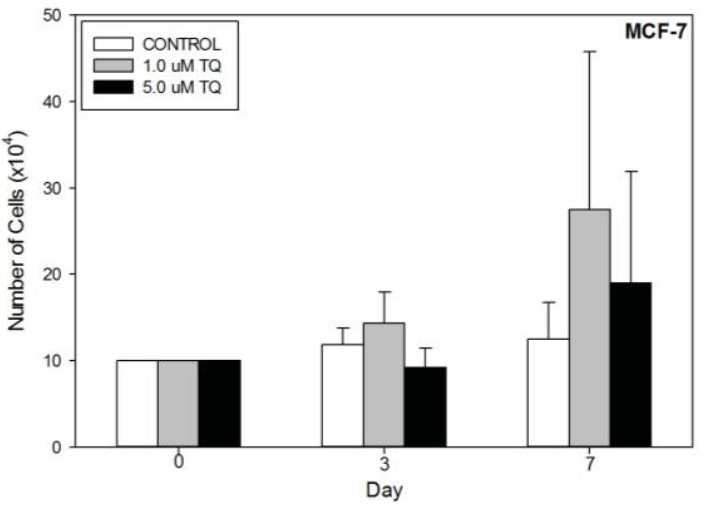

B

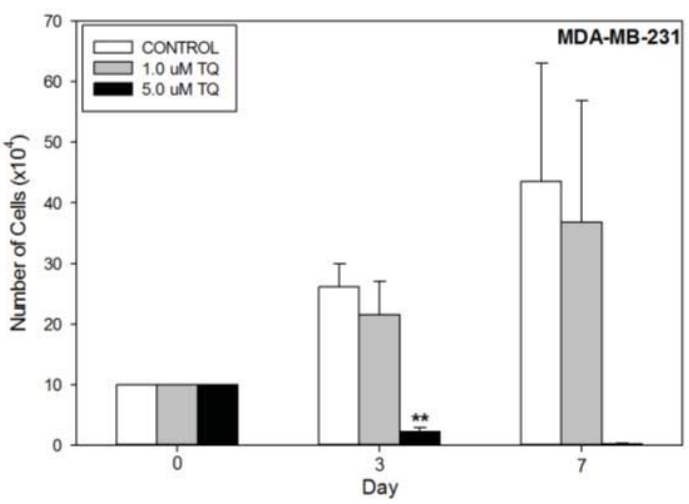

Figure 1. Cell proliferation of MCF-7 (A, C) and MDA-MB-231 (B, D) cell lines in presence of blackseed oil (A-B) and thymoquinone.(C-D) * represents statistical significance $\mathrm{p}<0.05$ and $* *$ represents statistical significance $\mathrm{p}<0.01$ compared to control. 


\section{Blackesed oil and thymoquinone do not affect cell adhesion}

More aggressive cell phenotypes are more motile and it is easier for these cells to make and break strong cell adhesions. To test the adhesion abilities of MCF-7 and MDA-MB-231 cells when treated with blackseed oil and thymoquinone, an adhesion assay was run for 30 minutes with and without treatments. Treatment groups for both blackseed oil and thymoquinone showed no significant differences compared to the control groups, indicating that these solutions had no effect on the adhesion ability of MCF-7 and MDA-MB-231 cells (Figure 2A, 2B).
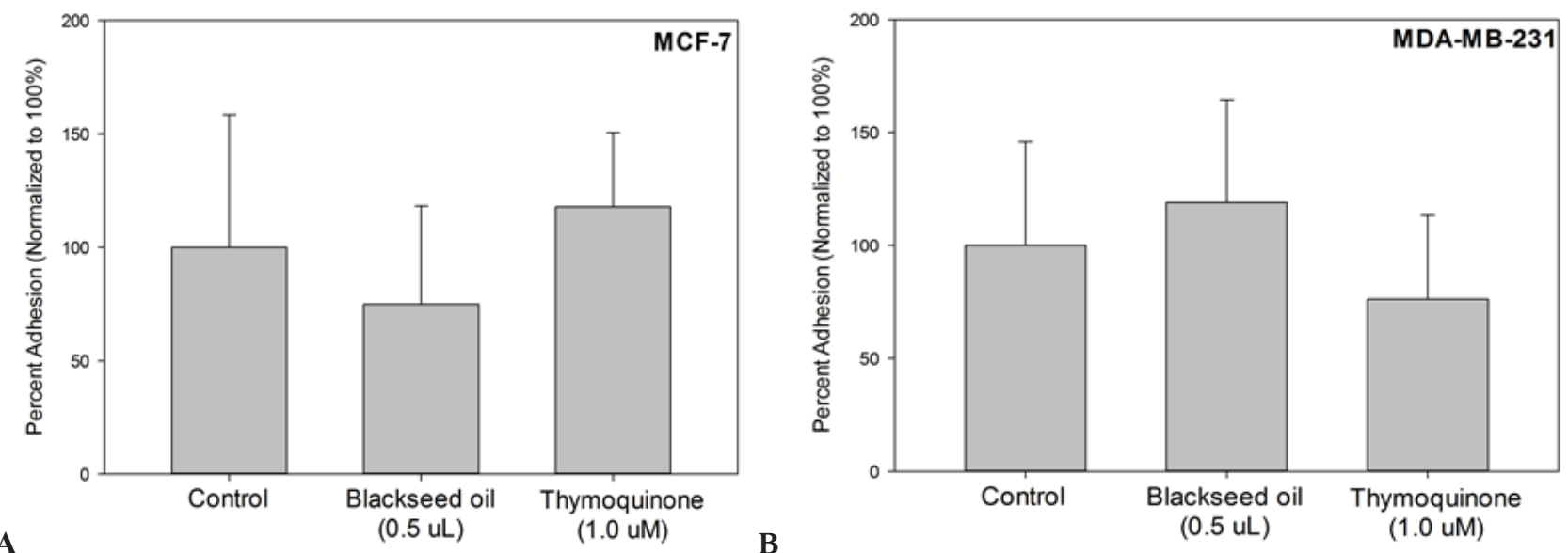

Figure 2. Cell adhesion assay of (A) MCF-7 and (B) MDA-MB-231 cell lines in presence of blackseed oil and thymoquinone.

\section{Blackseed oil and thymoquinone cause decreased growth in soft agar}

To test the ability of MCF-7 and MDA-MB-231 cells to grow in an anchorage-independent manner, a common sign of tumor progression in cancer cells, a soft agar assay was done in the presence of blackseed oil and thymoquinone. Both MCF-7 and MDA-MB-231 cells demonstrated significantly lower growth in soft agar with treatment of blackseed oil and thymoquinone compared to the control (Figure 3). Furthermore, growth of aggressive MDA-MB-231 cells was significantly inhibited compared to non-aggressive MCF-7 cells in the presence of thymoquinone. This indicates that treatment with blackseed oil and thymoquinone decreases the aggressive phenotype of MCF-7 and MDA-MB-231 and that invasive/metastatic MDAMB-231 cells are more susceptible to thymoquinone than their non-aggressive counterparts.

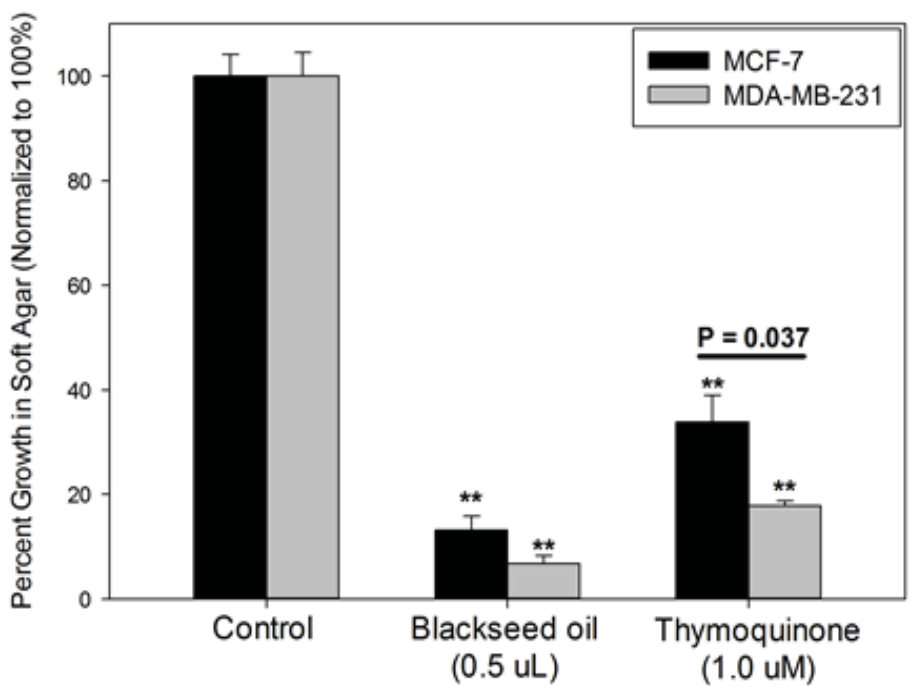

Figure 3. Percent cell growth in soft agar for MCF-7 and MDA-MB-231 cell lines in presence of blackseed oil and thymoquinone.** indicates p<0.001 compared to control. $\mathrm{P}=0.037$ (shown on graph) indicates colony growth of MDA-MB-231 compared to MCF-7. 


\section{DISCUSSION}

Given the unfavorable prognosis of individuals diagnosed with breast cancer-with the 5-year survival rate for females diagnosed with invasive breast cancer found to be as low as $26 \%$-it is imperative to find a novel therapeutic method. ${ }^{2}$ Therefore, the data presented in this paper demonstrate the effectiveness of blackseed oil and its active ingredient, thymoquinone, on limiting the aggressive phenotype of breast cancer cells. Although some of the results presented here do not reach significance, as noted in the above section, the general trends observed in the results of this study do provide valuable information regarding the effects of blackseed oil and TQ on both non-aggressive MCF-7 and aggressive MDA-MB-231 breast cancer cells.

In Figure 1, cell proliferation assay results are seen for both MCF-7 and MDA-MB-231 cell lines in the presence of varying concentrations of blackseed oil or TQ. Overall, the results shown in this figure are all in agreement with previous works exhibiting the effectiveness of blackseed oil and/or its active ingredient, TQ, in suppressing growth of a variety of cancerous cells_-including cancerous cells of the colon, lungs, pancreas, and other cancers. ${ }^{6-9}$ An analysis of key points of the figure proved to be quite interesting in this study. In Figure 1A, a general trend was seen where growth of MCF-7 cells treated with blackseed oil was generally greater than that of the control cells, which instead seemed to be dying. This trend was seen to be more prominent at the higher concentration of the oil $(1.0 \mu \mathrm{L})$, as compared to the lower concentration $(0.5 \mu \mathrm{L})$, while control cells showed the highest death rate overall (Figure 1A). This is an interesting observation, as it would suggest that these particular, low doses of blackseed oil may actually aid in the growth of non-aggressive cell types, as MCF-7 are intended to model in this work. In Figure 1B, however, a completely different set of results was exhibited, where the effect of varying concentrations of blackseed oil on aggressive MDA-MB-231 cells was noted. Here, it was seen that the presence of blackseed oil inhibited MDA-MB-231 cell growth at both 0.5 and $1.0 \mu \mathrm{L}$ concentrations, while the control cells instead displayed increased growth in the first three days.

The fact that the MCF-7 cells showed increased growth in the presence of blackseed oil (Figure 1A), while the more aggressive MDA-MB-231 cells instead displayed significant reductions in cells (Figure 1B), proves to be quite interesting. This phenomenon suggests that low doses of blackseed oil may work to not only suppress the growth of aggressive cancer cells, as noted both in this study and a plethora of previous studies, but also to support the growth of non-aggressive cells in the body. ${ }^{6-9}$ Because one of the major issues seen with current forms of breast cancer therapy include the unnecessary death of normal cells of the body-leading to such negative side effects as ototoxicity, cardiotoxicity, infertility, premature menopause, osteoporosis, and other effects - treatment with blackseed oil would seem to be an ideal solution to this issue, where only aggressive cells seem to be negatively affected, while non-aggressive cells are positively affected..$^{3,4}$ These results give credence to the notion that the clinical use of blackseed oil for cancer treatment may not only work for targeted killing of aggressive cancerous cells, but also for aiding in the growth of non-aggressive cells in the body. Additionally, the results present a dichotomy between the effects of blackseed oil and TQ on estrogen receptor-positive MCF-7 cells versus estrogen receptor-negative MDA-MB-231 cells. ${ }^{19}$ As the presence of these chemicals seemed to have a positive effect on nonaggressive growth of MCF-7 cells at these concentrations, while inhibiting growth of aggressive MDA-MB-231, this may suggest that the mechanisms of action of blackseed oil and TQ are estrogen receptor-dependent. Future studies in which mechanistic actions of these solutions are studied, specifically in relation to the estrogen receptor, would help clarify why this phenomenon was observed, and whether or not the estrogen receptor and subsequent pathways are involved.

Previous literature focusing on the active ingredient of blackseed oil, TQ, has also been noted to have shown the effectiveness of the substance in fighting cancers of the larynx, colorectal area, brain, breasts, oral lining, blood, and a number of other cancers. ${ }^{9,11-17}$ However, research done on breast cancer cells was limited in the usefulness of its results by either use of excessively high concentrations of TQ on only a single form of breast cancer cells, as seen in one study, or the use of a lipid carrier molecule alongside TQ in another study, which may have affected the results. ${ }^{14,15}$ In order to find a minimal effective dosage of TQ in preventing the growth of aggressive breast cancer cells, as done with blackseed oil as seen above, without the interference of a lipid carrier molecule, this study utilized lower concentrations of TQ on both cell types. Figure $1 \mathrm{C}$ displays the growth of the MCF-7 cell lines treated with $1.0 \mu \mathrm{M}$ and $5.0 \mu \mathrm{M}$ thymoquinone over the span of a week. A general trend of increased cell growth for the treated groups, in comparison to the control, was observed from day three to day seven of the experiment, although decreased cell growth was observed in the $5.0 \mu \mathrm{M}$ group from day zero to day three. Nevertheless, the results of this figure again support the notion that even the active ingredient of blackseed oil, thymoquinone, seems to help support cell growth of non-aggressive cell lines, while preventing growth of the aggressive cell line.

Figure 1D displayed cell growth of MDA-MB-231 cells treated with TQ over the span of seven days. Here, it can be observed from the growth of the MDA-MB-231 cells treated with $5.0 \mu \mathrm{M}$ TQ that cell proliferation was significantly decreased at day three, compared to the control cells (Figure 1D). However, this figure suggested that the lower 
concentration of TQ did not decrease cell growth quite as significantly as the $5.0 \mu \mathrm{M}$ concentration. These results would support the use of $5.0 \mu \mathrm{M}$ TQ as a better dosage for destroying aggressive breast cancer cells, although this concentration was also noted to have slightly less positive effects on non-aggressive cells than the lesser, $1.0 \mu \mathrm{M}$ dosage, as described above.

The second part of this experiment tested for the effects of blackseed oil and TQ on adhesion of MCF-7 and MDA-MB-231 cells. As mentioned earlier, more aggressive phenotypes are capable of making and breaking strong cell adhesions. Thus, given the effectiveness of blackseed oil and TQ on decreasing cell proliferation of the aggressive MDA-MB-231 cells, while encouraging the growth of non-aggressive MCF-7 cells, it was expected that effects on cell adhesion would also be seen. The adhesion assay for MCF-7 cells treated with $0.5 \mu \mathrm{L}$ of blackseed oil and $1.0 \mu \mathrm{M}$ of thymoquinone exhibited no significant differences in comparison to each other or the control (Figure 2A). The adhesion assay for MDA-MB-231 cells treated with $0.5 \mu \mathrm{L}$ of blackseed oil and $1.0 \mu \mathrm{M}$ of thymoquinone revealed no significant differences from the control, either (Figure $2 \mathbf{B}$ ). While this was the case, it was seen that blackseed oil generally seemed to decrease the adhesion of MCF-7 cells, while increasing the adhesion of MDA-MB-231 cells, and TQ tended to have the exact opposite effects. These preliminary data indicate that the mechanism for action of blackseed oil and TQ is not by regulating adhesion formation in cells. While many studies have shown the effect of blackseed oil and TQ on cell proliferation ${ }^{6-9}$, none have provided a viable mechanism of action in cells. Therefore, these results, along with previous published data, support the need for further experimentation with greater sample size to determine the mechanism of action of TQ and blackseed oil.

Finally, a soft agar assay was run in order to test each cell line's ability to grow in an anchorage-independent manner upon treatment with $0.5 \mu \mathrm{L}$ of blackseed oil and $1.0 \mu \mathrm{M}$ of thymoquinone. In Figure 3, it was shown that treatment with both blackseed oil and thymoquinone exhibited a significant decrease in anchorage-independent growth of both the MCF-7 and MDA-MB-231 cells, as indicated by the results of the soft agar assay. These results correlate with the data observed in Figure 1 and indicate that blackseed oil and TQ appear to regulate a step in tumor progression to a more aggressive state. However, the precise mechanism is still unknown. Additionally, TQ induced a significant decrease in anchorage-independent cell growth of the MDA-MB-231 cells in comparison to the non-aggressive, MCF-7, breast cancer cells, supporting the idea that aggressive breast cancer cells are more susceptible to TQ than non-aggressive cells. These results are especially intriguing because all prior studies utilizing breast cancer cell lines were performed with such high dosages that no difference was observed between aggressive and non-aggressive cancer cell lines. ${ }^{14}$ The results presented here are the first, to our knowledge, to indicate that aggressive cells may be more susceptible to TQ than non-aggressive cells which could have important clinical ramifications.

Although some of the results presented here did not reach significance, the general trends depicted certainly suggest the effectiveness of each substance tested - blackseed oil and its active ingredient TQ - at suppressing the growth of aggressive MDA-MB-231 cells, while possibly even supporting the growth of non-aggressive cells treated with the same substances. These data reinforce the results of previous works showing the effectiveness of blackseed oil and/or TQ at suppressing cancerous cell growth. ${ }^{6-9,11-17}$ Moreover, the current tests also supported the use of as low a clinically effective dose of blackseed oil as $0.5 \mu \mathrm{L}$, although the $1.0 \mu \mathrm{L}$ dose seemed to show better results and even earlier significance at killing aggressive breast cancer cells, while still supporting non-aggressive cell growth. The experiments also support the use of as little as a $5.0 \mu \mathrm{M}$ dosage of TQ, at which point aggressive breast cancer cell growth was again suppressed, while nonaggressive cell growth was supported. These points are especially important to make, as previous literature has been seen to have shown the death of both non-aggressive and aggressive breast cancer cell lines in the presence of TQ. ${ }^{14}$ However, the experiments conducted in those cases utilized extremely high dosages of TQ - even as high as $80 \mu \mathrm{M}-$ and thus did not provide information on the minimal dosage of TQ or blackseed oil that would be effective at suppressing aggressive cancer cell growth, while supporting the growth of non-aggressive cells. The data presented here do provide such suggested dosages, as mentioned above, and the effectiveness of the lower dosages is more clinically relevant. Interestingly, it was noted in the course of this study that thymoquinone generally took more time than blackseed oil to induce changes in proliferation. This may have indicated the presence of some other compound in the blackseed oil, aside from TQ, that would support the effects described here. This may be a point to note for further study.

\section{CONCLUSIONS}

Taken together, the data indicate the potential of blackseed oil and its active ingredient, thymoquinone, to combat breast cancer by limiting cancer progression to a less aggressive phenotype through decreased cell proliferation and anchorageindependent growth. This study is the first to provide a clinically relevant, minimal effective dosage of blackseed oil and thymoquinone. Further studies to elucidate the mechanism by which blackseed oil and TQ function in breast cancer cells may lead to novel treatments in the future. 


\section{ACKNOWLEDGMENTS}

This work was supported by the Ellen Marks Cancer Foundation (SLR).

\section{AUTHOR CONTRIBUTIONS}

Conceived and designed the experiments: SC SS TKS SLR. Performed the experiments: SC SS TKS. Analyzed the data: SC SS TKS. Contributed reagents/materials/analysis tools: SS SLR. Wrote the paper: SC SS TKS SLR. All student authors contributed equally to this work.

\section{REFERENCES}

1. American Cancer Society, Inc. Cancer Facts and Figures. http://www.cancer.org (accessed May 2016)

2. American Cancer Society, Inc. Breast Cancer Facts and Figures. http://www.cancer.org (accessed May 2016

3. Eryilmaz, A., Demirci, B., Gunel, C., Eliyatkin, N., Aktas, S., Omurlu, I. K., Basal, Y., Sagiroglu, M., Ermisler, B., Basak, S. (2016) Evaluation of lapatinib and trastuzumab for ototoxic effects, J Int Adv Otol 11, 207-211.

4. Ewertz, M., Jensen, A. B. (2011) Late effects of breast cancer treatment and potentials for rehabilitation, Acta Oncol 50, 187-193.

5. Singh, S., Das, S. S., Singh, G., Schuff, C., Lampasona, M. P. D., Catalán, C. A. N. (2014) Composition, in vitro antioxidant and antimicrobial activities of essential oil and oleoresins obtained from black cumin seeds (Nigella sativa L.), Biomed Res Int 2014, 1-10.

6. Salim, E. I., Fukushima, S. (2003) Chemopreventive potential of volatile oil from black cumin (Nigella sativa L.) seeds against rat colon carcinogenesis, Nutr Cancer 45, 195-202.

7. Al-Sheddi, E. S., Farshori, N. N., Al-Oqail, M. M., Musarrat, J., Al-Khedhairy, A. A., Siddiqui, M. A. (2014) Cytotoxicity of Nigella sativa seed oil and extract against human lung cancer cell line, Asian Pac J Cancer Prev 15, 983-987.

8. Banerjee, S., Kaseb, A. O., Wang, Z., Kong, D., Mohammad, M., Padhye, S., Sarkar, F. H., Mohammad, R. M. (2009) Antitumor activity of gemcitabine and oxaliplatin is augmented by thymoquinone in pancreatic cancer, Cancer Res 69, $5575-5583$.

9. Khan, A., Chen, H. C., Tania, M., Zhang, D. Z. (2011) Anticancer activities of Nigella sativa (black cumin), Afr J Tradit Complem 8, 226-232.

10. Şeleci, D. A., Gümüş, Z. P., Yavuz, M., Şeleci, M., Bongartz, R., Stahl, F., Coşkunol, H., Timur, S., Scheper, T. (2015) A case study on in vitro investigations of the potent biological activities of wheat germ and black cumin seed oil, Turk J Chem 39, 801-812.

11. Rooney, S., Ryan, M. F. (2005) Effects of alpha-hederin and thymoquinone, constituents of Nigella sativa, on human cancer cell lines, Anticancer Res 25, 2199-2204.

12. Gali-Muhtasib, H., Diab-Assaf, M., Boltze, C., Al-Hmaira, J., Hartig, R., Roessner, A., Schneider-Stock, R. (2004) Thymoquinone extracted from blackseed triggers apoptotic cell death in human colorectal cancer cells via a p53dependent mechanism, Int J Oncol 25, 857-866.

13. Gurung, R. L., Lim, S. N., Khaw, A. K., Soon, J. F. F., Shenoy, K., Ali, S. M., Jayapal, M., Sethu, S., Baskar, R., Hande, M. P. (2010) Thymoquinone induces telomere shortening, DNA damage and apoptosis in human glioblastoma cells, PLoS ONE 5, e12124.

14. Dastjerdi, M., Mehdiabady, E., Iranpour, F., Bahramian, H. (2016) Effect of thymoquinone on P53 gene expression and consequence apoptosis in breast cancer cell line, Int J Prev Med 7, 66.

15. Ng, W. K., Yazan, L. S., Yap, L. H., Wan Nor Hafiza, W. A., How, C. W., Abdullah, R. (2015) Thymoquinone-loaded nanostructured lipid carrier exhibited cytotoxicity towards breast cancer cell lines (MDA-MB-231 and MCF-7) and cervical cancer cell lines (HeLa and SiHa), Biomed Res Int 2015, 263131.

16. Abdelfadil, E., Cheng, Y. H., Bau, D. T., Ting, W. J., Chen, L. M., Hsu, H. H., Lin, Y. M., Chen, R. J., Tsai, F. J., Tsai, C. H. (2013) Thymoquinone induces apoptosis in oral cancer cells through P38ß inhibition, Am J Chin Med 41, 683-696.

17. El-Mahdy, M. A., Zhu, Q., Wang, Q. E., Wani, G., Wani, A. A. (2005) Thymoquinone induces apoptosis through activation of caspase-8 and mitochondrial events in p53-null myeloblastic leukemia HL-60 cells, Int J Cancer 117, $409-417$.

18. Topczewska, J. M., Postovit, L. M., Margaryan, N. V., Sam, A., Hess, A. R., Wheaton, W. W., Nickoloff, B. J., Topczewski, J., Hendrix, M. J. C. (2006) Embryonic and tumorigenic pathways converge via nodal signaling: role in melanoma aggressiveness, Nat Med 12, 925-932.

19. Dore-Savard, L., Lee, E., Kakkad, A., Popel, S., Bhujwalla, ZM. (2016) The Angiogenic Secretome in VEGF Overexpressing Breast Cancer Xenografts. Sci Rep 6, 39460. 


\section{ABOUT THE STUDENT AUTHORS}

Sabrina Chaudhry graduated from Elmhurst College in 2016 with her Bachelor of Science degree in Biology and a minor in Chemistry. She is currently applying to medical school.

Safia Siddiqui graduated from Elmhurst College in May of 2017 with a Bachelor of Science degree in Biology and minors in Chemistry and Medical Humanities. Her future goals include pursuing a career as an osteopathic physician.

Tyrnnon Steffen graduated from Elmhurst College in May of 2016 with a Bachelor of Science degree in Biology and a minor in Chemistry. She hopes to attend graduate school in the future.

\section{PRESS SUMMARY}

Breast cancer remains as the second leading cause of cancer deaths in women within the United States with limited treatment options that exhibit a variety of harmful side effects. Blackseed oil and its active ingredient, thymoquinone, are natural remedies that have recently demonstrated their effectiveness in limiting proliferation of breast cancer cells. However, previous studies have only exhibited this phenomenon at compound concentration levels that are too high to be clinically relevant. This study illustrates the effectiveness of low concentrations of blackseed oil and thymoquinone on limiting the aggressive phenotype of breast cancer cells through the suppression of cell proliferation and anchorage-independent growth. 